\title{
Sonographic Estimation of the Fetal Head Circumference: Accuracy and Factors Affecting the Error
}

\author{
Vidyashree Ganesh Poojari ${ }^{1}\left[\right.$. Aiswarya Jose ${ }^{1} \cdot$ Muralidhar V. Pai $^{1}$
}

Received: 23 June 2021 / Accepted: 22 September 2021 / Published online: 9 October 2021

(c) The Author(s) 2021

\begin{abstract}
Background Sonographic measurement of fetal head circumference (HC) is an essential parameter for the estimation of fetal weight as well as in cases with abnormal fetal head size. Since there is a lack of data, the present study was to assess the accuracy of ultrasonographic estimation of fetal $\mathrm{HC}$ and to identify factors that affect the accuracy of fetal $\mathrm{HC}$ estimation.

Material and Methods A prospective cohort observational study was conducted for a year. Sonographic fetal biometry including $\mathrm{HC}$ was performed, and fetal $\mathrm{HC}$ was measured postnatally. Measures of accuracy and various factors which affect the accuracy are analyzed.

Results Ultrasonographic HC underestimated actual postnatal HC in $87.5 \%$ and overestimated actual HC in $12.5 \%$. Sonographic underestimation of $\mathrm{HC}$ persisted throughout gestation and became more pronounced as gestational age increased. Error in HC was statistically significant in those with low liquor and anterior placenta and in those who had instrumental delivery. Parity, fetal presentation, and maternal diabetes did not affect the error in ultrasonographic measurement of head circumference. When the $\mathrm{HC}$ was beyond 95 th centile on ultrasound, the error detected postnatally was significant $(-14 \mathrm{~mm}$ vs. $-8 \mathrm{~mm}$ ), though not statistically significant ( $p$ value 0.82 ). The difference between the sonographic and postnatal HC was also related to the mode of delivery with the highest error seen in those who had instrumental vaginal delivery ( $p$ value 0.031 ). Conclusion The ultrasound estimation of fetal $\mathrm{HC}$ is associated with significant underestimation of the actual HC measured postnatally. The error in measuring fetal $\mathrm{HC}$ increased in those with advanced gestational age, low liquor, and anterior location of the placenta and in those who had instrumental vaginal delivery. The measurement error may have important implications in specific clinical scenarios like monitoring pregnancy with fetal growth restriction, suspected fetal head growth abnormalities, and labor outcome.
\end{abstract}

Keywords Fetal head circumference $\cdot$ Postnatal head circumference $\cdot$ Accuracy $\cdot$ Error

\section{Introduction}

Vidyashree Ganesh Poojari is an Associate Professor, Department of Obstetrics and Gynecology, Kasturba Medical College, Manipal Academy of Higher Education (MAHE), Manipal, Karnataka, India; Aiswarya Jose is a Junior Resident, Department of Obstetrics and Gynecology, Kasturba Medical College, Manipal Academy of Higher Education (MAHE), Manipal, Karnataka, India; Muralidhar V. Pai is a Professor and Unit Head, Department of Obstetrics and Gynecology, Kasturba Medical College, Manipal Academy of Higher Education (MAHE), Manipal, Karnataka, India.

Vidyashree Ganesh Poojari

drvidyaganesh@gmail.com

1 Department of Obstetrics and Gynecology, Kasturba Medical College, Manipal, Manipal Academy of Higher Education (MAHE), Manipal, Karnataka, India
Assessment of fetal biometry by ultrasound is an essential and universal part of antenatal care, not only in managing highrisk pregnancies and growth monitoring but also vital in labor outcome [1]. Sonographic measurement of fetal head circumference (HC) is an essential parameter for the estimation of fetal weight as well as in cases with abnormal fetal head size (i.e., microcephaly/macrocephaly) [2,3]. Lately, studies have shown that fetal head circumference is more important than fetal weight in the labor outcome [4-6]. Hence, measuring fetal head circumference is of utmost importance with precision. However, few studies are found regarding the accuracy of sonographic estimation of $\mathrm{HC}$ compared with actual postnatal $\mathrm{HC}$ during the literature search. Some studies found that the sonographic head circumference underestimated actual HC, 
while others found that the difference was statistically insignificant [7]. There is also a lack of data on factors affecting the accuracy of estimation of ultrasonographic fetal HC.

Our study aimed to assess the accuracy of ultrasonographic estimation of fetal $\mathrm{HC}$ in a cohort of women undergoing sonographic examination within 5 days before delivery and also to identify factors that affect the accuracy of ultrasonographic estimation of fetal HC.

\section{Materials and Methods}

The present study was a prospective cohort observational study conducted for a year in a tertiary care referral hospital. After informed written consent, we considered antenatal history, demographic characteristics, gestational age at delivery, and mode of delivery. Certain factors which may affect the accuracy like parity, fetal presentation, placental location, amniotic fluid index (AFI), ultrasonographic HC $>95$ th centile, and diabetic status were analyzed.

Inclusion criteria for the study were all antenatal women with a singleton pregnancy, those who delivered live babies with gestational age beyond 28 weeks. We excluded multiple pregnancies, cases in which there was uncertainty regarding gestational age, and anomalous babies from the study.

A senior consultant in the ultrasound unit of the obstetrics and gynecology department performed a detailed growth scan within 5 days of delivery-fetal biometry measured as per the ISUOG guidelines [8]. The HC was measured as an ellipse around the perimeter of the fetal skull on an axial plane that traverses the thalami and cavum septum pellucidum. The transducer must be perpendicular to the central axis of the head, so that the hemispheres and calvaria should appear symmetric. Cerebellar hemispheres should not be in the plane of the image. Ellipse was traced at the outer skull border (Fig. 1).

The actual postnatal head circumference was measured by a trained pediatrician 3 days after delivery using a measuring tape over the supraorbital ridge and occipital prominence (Fig. 2). This delay of 3 days minimized the measurement error caused by scalp edema, caput succedaneum. Sonographic estimations of fetal $\mathrm{HC}$ were compared with the actual $\mathrm{HC}$ measured postnatally, and then the accuracy measures were calculated. Mean simple error is the difference between the ultrasonographic $\mathrm{HC}$ and postnatal $\mathrm{HC}$. The study was approved by the institutional ethical review board (IEC 514/2017).

\section{Statistical Analysis}

We performed data analysis using SPSS 20 software. One sample $t$ test is used to determine the sample size. While comparing measures of accuracy, one-way ANOVA was

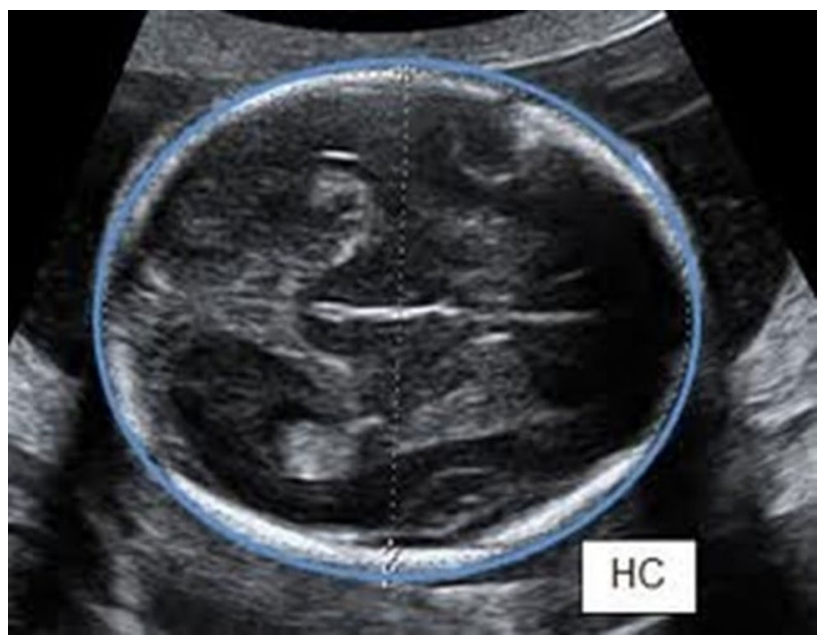

Fig. 1 Ultrasonographic image of measuring fetal head circumference

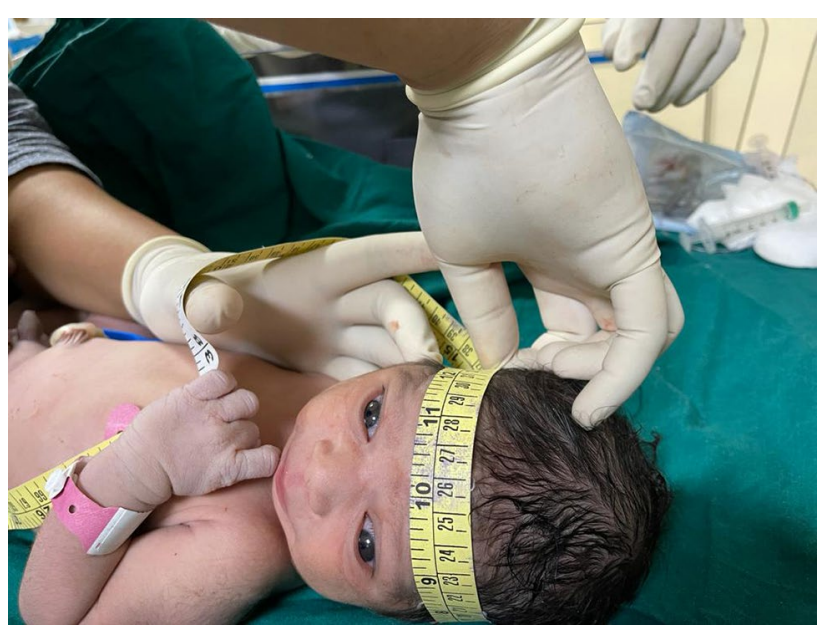

Fig. 2 Measuring head circumference of the new born using a measuring tape

used for the mean simple error. Univariate logistic regression analysis was used to analyze various factors affecting the errors in measurement of fetal HC. Pearson's correlation coefficient was used to determine significance in the correlation of various parameters with actual HC. $p$ value was significant if differences were $<0.05$.

\section{Results}

A total of 242 women met the inclusion criteria for the study during the study period, out of which 216 (89.25\%) were recruited for the study and analyzed. The remaining $26(10.7 \%)$ were unwilling to participate in the study or lost to follow-up. 
Table 1 Demographic characteristics of the study population $(N=216)$

\begin{tabular}{ll}
\hline Characteristics & Mean \pm SD \\
\hline Age (years) & $26.85 \pm 3.7$ \\
Gestational age (weeks) & $36.8 \pm 2.8$ \\
Ultrasonographic HC (mm) & $315.3 \pm 19.1$ \\
Actual postnatal HC (mm) & $323.7 \pm 28.8$ \\
Ultrasonographic estimated fetal weight (grams) & $2711 \pm 642$ \\
Actual birth weight (grams) & $2624 \pm 595$ \\
Diabetes in pregnancy & $15(6.9 \%)$ \\
\hline
\end{tabular}

Table 1 shows the demographic characteristics of the study group. The mean age of the antenatal women was $26.85 \pm 3.7$ years. The mean gestational age in weeks was $36.8 \pm 2.8$. The mean ultrasonographic HC in millimeters $(\mathrm{mm})$ was $315.3 \pm 19.1$. The mean actual postnatal HC was $323.7 \pm 28.8 \mathrm{~mm}$. The mean estimated fetal weight on ultrasound was $2711 \pm 642 \mathrm{~g}$. The mean actual birth weight was $2624 \pm 595$ g. Fifteen $(6.9 \%)$ women had diabetes in pregnancy.

Overall, the mean sonographic fetal $\mathrm{HC}$ was lower than the postnatal HC (Table 1). The tendency for sonographic underestimation of $\mathrm{HC}$ persisted throughout gestation and became more distinct as gestational age increased, reaching a mean difference of $-8.9 \mathrm{~mm}$ at gestational age beyond 37 weeks (Table 2). Ultrasonographic HC underestimated actual postnatal HC in 189 cases $(87.5 \%)$ and overestimated actual $\mathrm{HC}$ in 27 cases (12.5\%).

Table 2 presents various demographic, obstetric, and sonographic parameters that were thought to have a potential effect on HC error. The error in HC measurement and the degree of underestimation were significantly higher in gestational age beyond 34 weeks, with an error of $8.1 \mathrm{~mm}$ between 34 and $36^{+6}$ weeks and $8.9 \mathrm{~mm}$ beyond 37 weeks. Error in $\mathrm{HC}$ was significantly more in those with the anterior location of the placenta $(9.3 \mathrm{~mm})$ when compared to posterior $(8.4 \mathrm{~mm})$ and fundal location $(4.2 \mathrm{~mm})$ of the placenta.

Women with an amniotic fluid index less than 5 had a significantly higher error $(-12 \mathrm{~mm}, p$ value 0.056$)$ when compared to normal liquor. Parity, maternal diabetes, and fetal presentation did not affect the error in ultrasonographic measurement of head circumference.

The difference between the sonographic and postnatal $\mathrm{HC}$ was also related to the mode of delivery, highest error in those who had instrumental delivery $(-13 \mathrm{~mm})$. It was also noteworthy that when the $\mathrm{HC}$ was beyond 95th centile on ultrasound, the error detected postnatally was significant $(-14 \mathrm{~mm}$ vs. $-8 \mathrm{~mm})$, though not statistically significant ( $p$ value 0.82 ).
Table 2 Factors contributing to the accuracy of measuring fetal head circumference $(N=216)$

\begin{tabular}{|c|c|c|c|}
\hline Variables & $N=216$ & $\begin{array}{l}\text { Mean simple error } \\
(\mathrm{mm})\end{array}$ & $p$ value* \\
\hline \multicolumn{4}{|l|}{ Parity } \\
\hline Primigravida & 148 & -6.5 & \multirow[t]{2}{*}{0.123} \\
\hline Multigravida & 68 & -9.4 & \\
\hline \multicolumn{4}{|c|}{ Gestational age (weeks) } \\
\hline $28-33^{+6}$ & 32 & -5 & \multirow[t]{3}{*}{0.035} \\
\hline $34-36^{+6}$ & 53 & -8.1 & \\
\hline$>37$ & 131 & -8.9 & \\
\hline \multicolumn{4}{|c|}{ Diabetes in pregnancy } \\
\hline Present & 15 & -13.0 & \multirow[t]{2}{*}{0.407} \\
\hline Absent & 201 & -8.03 & \\
\hline \multicolumn{4}{|l|}{ Presentation } \\
\hline Vertex & 201 & -8.40 & \multirow[t]{2}{*}{0.507} \\
\hline Breech & 15 & -8.00 & \\
\hline \multicolumn{4}{|c|}{ Placental location } \\
\hline Anterior & 70 & -9.3 & \multirow[t]{3}{*}{0.040} \\
\hline Posterior & 128 & -8.4 & \\
\hline Fundal & 18 & -4.2 & \\
\hline \multicolumn{4}{|c|}{ Amniotic fluid index } \\
\hline $8-25$ & 160 & -7.4 & \multirow[t]{3}{*}{0.056} \\
\hline $5-8$ & 43 & -8.4 & \\
\hline$<5$ & 12 & -12 & \\
\hline \multicolumn{4}{|c|}{$H C>95$ th centile } \\
\hline Present & 13 & -14 & \multirow[t]{2}{*}{0.825} \\
\hline Absent & 203 & -8 & \\
\hline \multicolumn{4}{|c|}{ Mode of delivery } \\
\hline Normal & 105 & -9.4 & \multirow[t]{3}{*}{0.031} \\
\hline Instrumental & 3 & -13.5 & \\
\hline Cesarean & 108 & -7.1 & \\
\hline
\end{tabular}

$* p$ value $<0.05$ is considered significant

\section{Discussion}

In the present study, we evaluated the accuracy of measuring fetal head circumference on ultrasound by comparing it with the head circumference measured postnatally. We also looked into the factors affecting the accuracy of estimating sonographic HC.

Studies have shown that accurate measurement of fetal head circumference and fetal weight estimation by ultrasound are the essential prognostic parameters for many obstetric problems like evaluating the babies with fetal growth restrictions, fetal head anomalies in labor management by reducing the perinatal morbidity and mortality, and a beneficial tool for determining the further obstetric management [1, 9-11].

In the present study, the ultrasonographic head circumference was measured by eclipse that was traced all around the 
fetal skull within 5 days before delivery and was compared with actual $\mathrm{HC}$ postnatally measured 3 days after delivery. Overall, the mean sonographic $\mathrm{HC}$ was lower than the postnatal HC (Table 1). The sonographic underestimation of HC remained throughout gestation and became more striking as gestational age increased, reaching a mean difference of $-8.9 \mathrm{~mm}$ at gestational age beyond 37 weeks (Table 2). Ultrasonographic $\mathrm{HC}$ underestimated actual postnatal $\mathrm{HC}$ in 189 cases $(87.5 \%)$. Ultrasonographic $\mathrm{HC}$ overestimated actual HC in 27 cases (12.5\%). In a study by Melamed et al. [7], ultrasonographic fetal HC measurements taken within 3 days of delivery were compared with actual head circumference measurements taken postnatally within 2-6 h after delivery with a measuring tape. The current study showed significant underestimation of ultrasonographic HC measurements in comparison with the postnatally measured HC. Like in our study, Melamed et al. [7] also said that as the gestational age increased, the tendency for underestimation also increased.

We also studied the factors influencing the error in the estimation of ultrasonographic fetal HC. Gestational age, anterior location of the placenta, and low liquor of less than 5 had a statistically significant error in fetal HC, whereas parity, maternal diabetes, and fetal presentation did not affect the error in ultrasonographic measurement of head circumference.

A similar study conducted by Melamed et al. in 2011 [7] showed that the error in measuring fetal $\mathrm{HC}$ and the degree of underestimation were significantly higher in the case of gestational age $\geq 34$ weeks, fundal placenta, high cephalic index and postnatal $\mathrm{HC}>90$ th centile.

Wegrzyn et al. concluded that the influence of gestational age on measuring $\mathrm{HC}$ might be due to larger babies due to increased subcutaneous tissue [9].

Contrary to our results, Huber et al. in their systematic review on factors influencing the accuracy of fetal weight estimation (FWE) in preterm babies reported that maternal body mass index, gestational age, amniotic fluid index, presentation of the fetus, the presence of multiple fetuses and location of placenta do not seem to have an impact on the accuracy in fetal weight estimation. The influence of the sonologists expertise and fetal gender were discussed contentiously. The time interval between the fetal HC estimation and delivery, and varieties of formulas used to calculate FWE seem to have an evident effect on FWE accuracy [12].

In the present study, the difference between the sonographic and postnatal $\mathrm{HC}$ was also related to the mode of delivery with the highest error following instrumental vaginal delivery $(-13 \mathrm{~mm})$. It was also noteworthy that when the $\mathrm{HC}$ was beyond 95th centile on ultrasound, the error detected postnatally was significant $(-14 \mathrm{~mm}$ vs. $-8 \mathrm{~mm})$, though not statistically significant ( $p$ value 0.82 ). In their study, Melamed et al. [7] also stated that reduced ultrasound accuracy influenced delivery by vacuum extraction. Wegrzyn et al., in their study, stated that the error in HC depended on the mode of delivery. The error was least for cesarean sections and increased for vaginal deliveries and vacuum extraction [9].

Lipschuetz et al. [6], in their extensive retrospective analysis of 24,780 cases, studied if the fetal head, which interfaces with the birth canal, might impact obstetric outcomes more than birth weight. They analyzed the risk of unplanned cesarean or instrumental delivery, maternal and perinatal complications among those with $\mathrm{HC}$ or birth weight $\geq 95$ th centile. The study concluded that a large $\mathrm{HC}$ is strongly associated with unplanned cesarean and instrumental delivery than high birth weight. This result is significant to improve pre-labor counseling and clinical management of mothers with big babies. Hence, the accurate measurement of the fetal head circumference by ultrasound is more important than birth weight in assessing the mode of delivery.

Lipschuetz et al. [13], in another recent study published in 2018, analyzed the risk of undergoing unplanned cesarean in those with large fetal head circumference. He concluded that sonographic fetal $\mathrm{HC}>35 \mathrm{~cm}$ measured within a week of delivery is an independent risk factor for an unplanned cesarean section but not for instrumental delivery. Fetal head circumference $\geq 35 \mathrm{~cm}$ and estimated fetal weight $\geq 3900 \mathrm{~g}$ significantly increased the risk of a prolonged second stage of labor.

Strength and limitations of the study: This is a prospective study. The ultrasound was performed by a single senior consultant. Hence, the interobserver errors in calculating fetal $\mathrm{HC}$ are minimized. However, since the sample size was very small, further research with a larger sample size is required to generalize our study results.

\section{Conclusion}

The ultrasound estimation of fetal head circumference is associated with significant underestimation of the actual head circumference measured postnatally. The error in measuring fetal $\mathrm{HC}$ increases with advanced gestational age, low liquor, and anterior location of the placenta. Accurate measurement of fetal head circumference has important implications in specific clinical scenarios like monitoring pregnancy with fetal growth restriction, suspected fetal head growth abnormalities as well as labor management and perinatal outcomes. The error in fetal head circumference was more in those who had instrumental vaginal delivery. Hence, measuring accurate fetal head circumference in the last few days before delivery may be an important adjunct to estimated fetal weight in labor management and perinatal outcome. 
Funding Open access funding provided by Manipal Academy of Higher Education, Manipal. No funding.

\section{Declarations}

Conflict of interest Vidyashree Ganesh Poojari, Aiswarya Jose, and Muralidhar V Pai declare that they have no conflict of interest.

Ethical Approval Institutional Ethics Committee clearance was obtained (IEC Number-514/2017) from Kasturba Medical College and Kasturba Hospital, Manipal.

Informed Consent Informed consent was obtained from all patients for being included in the study.

Open Access This article is licensed under a Creative Commons Attribution 4.0 International License, which permits use, sharing, adaptation, distribution and reproduction in any medium or format, as long as you give appropriate credit to the original author(s) and the source, provide a link to the Creative Commons licence, and indicate if changes were made. The images or other third party material in this article are included in the article's Creative Commons licence, unless indicated otherwise in a credit line to the material. If material is not included in the article's Creative Commons licence and your intended use is not permitted by statutory regulation or exceeds the permitted use, you will need to obtain permission directly from the copyright holder. To view a copy of this licence, visit http://creativecommons.org/licenses/by/4.0/.

\section{References}

1. Ugwu EO, Udealor PC, Dim CC, et al. Accuracy of clinical and ultrasound estimation of fetal weight in predicting actual birth weight in Enugu, South-eastern Nigeria. Niger J Clin Pract. 2014;17(3):270-5.

2. Yang L, Ming ZP, Guo WT, et al. Effect of head circumference in combination with facial profile line on ultrasonic diagnosis of microcephaly. J Matern Fetal Neonatal Med. 2020;33(14):2372-6. https://doi.org/10.1080/14767058.2018.1551349.

3. Malini D, Flor MM, Erick S, et al. Congenital microcephaly: case definition \& guidelines for data collection, analysis, and presentation of safety data after maternal immunisation. Vaccine. 2017;35(48):6472-82. https://doi.org/10.1016/j.vaccine.2017. 01.044 .

4. Larson A, Mandelbaum DE. Association of head circumference and shoulder dystocia in macrosomic neonates. Matern Child Health J. 2013;17:501-4.

5. Mujugira A, Osoti A, Deya R, et al. Fetal head circumference, operative delivery, and fetal outcomes: a multi-ethnic populationbased cohort study. BMC Pregnancy Childbirth. 2013;13:106.

6. Lipschuetz M, Cohen SM, Ein-Mor E, et al. A large head circumference is more strongly associated with unplanned cesarean or instrumental delivery and neonatal complications than high birthweight. Am J Obstet Gynecol. 2015;213:833.e1-12.

7. Melamed N, Yogev Y, Danon D, et al. Sonographic estimation of fetal head circumference: how accurate are we? Ultrasound Obstet Gynecol. 2011;37:65-71.

8. ISUOG Practice Guidelines. Ultrasound assessment of fetal biometry and growth. Ultrasound Obstet Gynecol. 2019;53:715-23.

9. Wegrzyn P, Borowski D, Bomba-Opon D, et al. Accuracy of sonographic estimation of fetal head circumference. Ultrasound Obstet Gynecol. 2011;37(6):743.

10. Schmidt U, Temerinac D, Bildstein K, et al. Finding the most accurate method to measure head circumference for fetal weight estimation. Eur J Obstet Gynecol Reprod Biol. 2014;178:153-6. https://doi.org/10.1016/j.ejogrb.2014.03.047.

11. Said AS, Manji KP. Risk factors and outcomes of fetal macrosomia in a tertiary centre in Tanzania: a case-control study. BMC Pregnancy Childbirth. 2016;16:243. https://doi.org/10.1186/ s12884-016-1044-3.

12. Uber C, Zdanowicz JA, Mueller M, et al. Factors influencing the accuracy of fetal weight estimation with a focus on preterm birth at the limit of viability: a systematic literature review. Fetal Diagn Ther. 2014;36:1-8. https://doi.org/10.1159/000358518.

13. Lipschuetz M, Cohen SM, Israel A, et al. Sonographic large fetal head circumference and risk of cesarean delivery. Am J Obstet Gynecol. 2018;218:339.e1-7.

Publisher's Note Springer Nature remains neutral with regard to jurisdictional claims in published maps and institutional affiliations.

\section{About the Author}

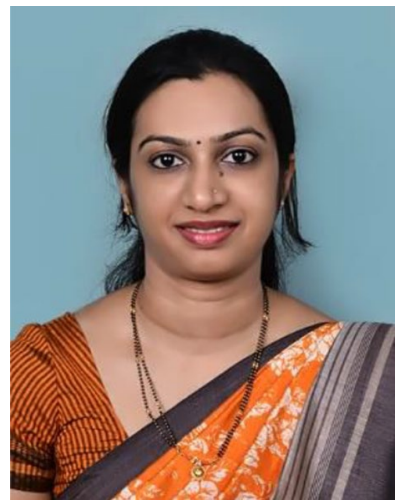

Dr. Vidyashree Ganesh Poojari (MS, DNB, MNAMS, ICOG Fellowship in Gynecological Endoscopy, Fellowship in Reproductive Medicine and surgery) is presently working as an Associate Professor in the Department of Obstetrics and Gynecology, Kasturba Medical College, Manipal Academy of Higher Education, Manipal, Karnataka, India. Her areas of interest are high-risk pregnancy, reproductive medicine, and minimal invasive pelvic surgeries. She is a member of Institutional Research Committee. She was Joint Secretary of Manipal OBG Society 2018-2020. 